\title{
Serum cystatin $C$ and the incidence of type 2 diabetes mellitus
}

\author{
K. Sahakyan • K. E. Lee • A. Shankar • R. Klein
}

Received: 20 September 2010 / Accepted: 25 January 2011 /Published online: 5 March 2011

(C) Springer-Verlag 2011

\begin{abstract}
Aims/hypothesis To examine the association of serum cystatin $\mathrm{C}$ with the incidence of type 2 diabetes mellitus over a 15 year follow-up period.

Methods The 15 year cumulative incidence of diabetes was measured in a cohort of Beaver Dam Eye Study participants $(n=3,472,1988-2003)$. A person was defined as developing diabetes (a positive history of diabetes mellitus treated with insulin, oral hypoglycaemic agents and/or diet, or elevations in glycosylated haemoglobin levels) in the absence of diabetes at baseline. The relation of cystatin $\mathrm{C}$ and other risk factors to incident type 2 diabetes was determined using discrete time extension of the proportional hazards model.

Results The 15 year cumulative incidence of diabetes was estimated to be $9.6 \%$. After controlling for age, sex, body mass index, smoking status, glycosylated haemoglobin, proteinuria, chronic kidney disease status and hypertension status, serum cystatin $\mathrm{C}$ at baseline was associated with the 15 year cumulative incidence of type 2 diabetes (OR per $\log$ of cystatin C unit 2.19, 95\% CI 1.02-4.68).

Conclusions/interpretation These findings show a positive relationship of serum cystatin $\mathrm{C}$ levels with the incidence of type 2 diabetes mellitus independently of confounding risk factors. The findings strongly suggest the need for further
\end{abstract}

K. Sahakyan $(\bowtie) \cdot$ K. E. Lee $\cdot$ R. Klein

Department of Ophthalmology and Visual Sciences,

University of Wisconsin-Madison,

610 N. Walnut Street, 4th Floor WARF,

Madison, WI 53726, USA

e-mail: sahakyan@epi.ophth.wisc.edu

A. Shankar

Department of Community Medicine,

West Virginia University School of Medicine,

Morgantown, WV, USA evaluation of the potential importance of cystatin $\mathrm{C}$ in the pathogenesis of type 2 diabetes mellitus.

Keywords Epidemiology · Pathogenic mechanisms . Prediction and prevention. Type 2 diabetes
Abbreviations
CKD Chronic kidney disease
hsCRP High-sensitivity C-reactive protein
MDRD Modification of Diet in Renal Disease

\section{Introduction}

Type 2 diabetes mellitus is common and an important cause of morbidity and mortality. Its incidence is expected to increase by two to three times over the next $30-40$ years, largely as a result of changes in diet and physical activity levels $[1,2]$. Other factors, such as smoking and renal disease, have also been shown to increase the risk of type 2 diabetes mellitus. Recent studies suggest that cystatin $\mathrm{C}$ is not only a sensitive marker of renal dysfunction but is also associated with insulin resistance, obesity and hypertension $[3,4]$. These conditions are known to be related to the development of type 2 diabetes $[5,6]$.

Serum cystatin $\mathrm{C}$ has been suggested to be associated with the risk of progression from normoglycaemia to prediabetes in Western New York Health Study participants [7]. To our knowledge, there are no population-based studies that have examined the association of serum cystatin $\mathrm{C}$ with the long-term incidence of type 2 diabetes mellitus. In this paper we examine this relationship in a cohort of participants in the Beaver Dam Eye Study. 


\section{Methods}

Population Methods used to identify and describe the population have appeared in previous reports [8-11]. In brief, a private census of the population of Beaver Dam, WI, USA, was performed from 15 September 1987 to 4 May 1988 to identify all residents in the city or township of Beaver Dam who were 43-84 years of age. Of the 5,924 eligible individuals, 4,926 participated in the baseline examination between 1 March 1988 and 14 September 1990 [8]. Ninety-nine per cent of the population was white. Of the 4,926 who were examined at baseline, 384 had died before the beginning of the 5 year follow-up examination. Of the 4,542 surviving persons, 3,684 (81.1\%) participated in the 5 year follow-up examination in 1993 to 1995 [9]. Of the 3,334 surviving participants in the baseline and second examination, $2,764(82.9 \%)$ participated in the 10 year follow-up examination [10]. Of the 2,480 surviving participants who were examined at the baseline and at 5 and 10 year follow-up examinations, 2,119 (85.4\%) participated in the 15 year follow-up examination [11]. Comparisons between participants and non-participants at the time of the baseline and 5, 10 and 15 year follow-up examinations have appeared elsewhere [8-11].

Procedures and definitions Similar procedures, used at both the baseline and follow-up examinations, have been described in detail elsewhere $[12,13]$. Informed consent was obtained from each participant at the beginning of the examination, and all examinations followed a similar protocol that was approved by the Institutional Review Board of the University of Wisconsin and carried out in accordance with the Declaration of Helsinki.

Casual blood specimens and non-fasting blood specimens were obtained from participants. Serum glucose level was determined using the hexokinase method. During the first two examination phases, $\mathrm{HbA}_{1 \mathrm{c}}$ was determined using affinity chromatography (Isolab, Akron, OH, USA). During the third examination phase, total glycosylated haemoglobin was measured using the ion capture method (IMX; Abbott Laboratories, North Chicago, IL, USA). During the fourth examination phase, glycosylated haemoglobin $\mathrm{A}_{1 \mathrm{c}}$ was measured using high-performance liquid chromatography (A1c 2.2 Plus; Tosoh Corporation, Tokyo, Japan). Total glycosylated haemoglobin from the first three examination phases was standardised to the percentage of glycosylated haemoglobin $\mathrm{A}_{1 \mathrm{c}}$ using the formula: glycosylated haemoglobin $\mathrm{A}_{1 \mathrm{c}}=($ glycosylated haemoglobin +1.76$) / 1.49$. Diabetes was defined as present regardless of $\mathrm{HbA}_{1 \mathrm{c}}$ level if a person had been told by a physician that he/she had diabetes mellitus and was treated with insulin, oral hypoglycaemic agents and/or diet. In persons diagnosed to have diabetes by a physician but not on treatment, diabetes was defined as present if $\mathrm{HbA}_{1 \mathrm{c}}$ was $\geq 6.5 \%$. Primary care physicians were consulted whenever there was doubt about past diagnosis. Newly identified diabetes was defined as an $\mathrm{HbA}_{1 \mathrm{c}}$ level $\geq 7.0 \%$ in a person who had not been previously told by a physician that he/she had diabetes. A person was defined as suspected of having diabetes if he/ she had a positive history of diabetes, but was not treated with medications and/or diet and $\mathrm{HbA}_{1 \mathrm{c}}$ levels were $<6.5 \%$. Cumulative incidence of type 2 diabetes mellitus was defined as it being present at any follow-up examination in persons in whom it was absent at the 1988-1990 baseline examination. Persons who were suspected of having diabetes were excluded from these analyses.

Remaining serum was stored without preservative at $-80^{\circ} \mathrm{C}$ in cryogenic vials with O-rings for up to 17 years until the vials were shipped on dry ice to the University of Minnesota laboratory for the analyses reported here. Creatinine was measured in serum by reflectance spectrophotometry on a Vitros analyser (Johnson \& Johnson Clinical Diagnostics, Rochester, NY, USA). The laboratory $\mathrm{CV}$ was $2.2 \%$. High-sensitivity C-reactive protein (hsCRP) was measured with a Hitachi 911 (Roche Diagnostics, Indianapolis, IN, USA) using the CRP K-Assay, a particleenhanced immunonephelometric assay (Kamiya Biomedical Company, Seattle, WA, USA). The expected normal values are $\leq 5 \mathrm{mg} / \mathrm{l}$ and the laboratory $\mathrm{CV}$ ranged from $2.1 \%$ to $4.5 \%$. Serum cystatin $\mathrm{C}$ was determined nephelometrically using a BN100 nephelometer (Dade Behring, Deerfield, IL, USA). The interassay precision was determined at two control levels: $1.72 \mathrm{mg} / \mathrm{l}(\mathrm{CV} 6.4 \%)$ and $0.78 \mathrm{mg} / \mathrm{l}(\mathrm{CV}$ $5.2 \%)$. GFR was estimated based on the four-variable Modification of Diet in Renal Disease (MDRD) Study equation $\left(\mathrm{GFR}=175 \times(\text { serum } \text { creatinine } / 88.4)^{-1.154} \times\right.$ age $^{-0.203} \times 1.212$ [if black] $\times 0.742$ [if female]) [14] used when serum creatinine is reported in $\mu \mathrm{mol} / 1$. In addition, GFR was calculated based on serum cystatin $C$ levels using the formula $\left(\mathrm{GFR}=127.7 \times\right.$ serum cystatin $\mathrm{C}^{-1.17} \times \mathrm{age}^{-0.13} \times$ 1.06 [if black] $\times 0.91$ [if female]) [15]. Gross proteinuria was determined by dipstick on a casual urine sample and defined as a urinary protein concentration $>0.3 \mathrm{~g} / \mathrm{l}$.

Age was defined as the age at the time of the 1988-1990 examination. Cigarette smoking status was determined as follows: a participant was classified as a non-smoker if he/ she had smoked fewer than 100 cigarettes in his/her lifetime; as an ex-smoker if he/she had smoked 100 or more cigarettes in his/her lifetime but had stopped smoking before the examination; and as a current smoker if he/she had not stopped smoking. Hypertension was defined as a mean systolic BP of $\geq 140 \mathrm{mmHg}$ and/or a mean diastolic BP of $\geq 90 \mathrm{mmHg}$ and/or a history of hypertension using antihypertensive medication at the time of the baseline examination. BMI was defined as weight in kilograms divided by height in metres squared. A person was defined 
as having a history of cardiovascular disease at the 19881990 examination based on the participant's history of angina, myocardial infarction or stroke. A person was defined as having a sedentary lifestyle based on a history of exercise less than three times per week.

Statistical analysis The cumulative 15 year incidence of diabetes mellitus was estimated accounting for the competing risk of death [16]. Associations between serum cystatin $\mathrm{C}$ and other risk factors with time to the development of incident diabetes were assessed using the discrete time extension of the proportional hazards model [17] as implemented in the PROC PHREG procedure (SAS Institute, Cary, NC, USA). Effects of covariates on the discrete hazard function are summarised as OR and $95 \% \mathrm{CI}$ as implemented in the PROC PHREG procedure (SAS Institute). These analytical approaches allowed those people who were not seen after the 5,10 or 15 year examination because of death or non-participation to contribute information to the estimates [16, 18]. The assumption of proportionality (constant OR over time) was assessed graphically for all covariates [19]. Analyses were stratified based on baseline smoking status because of nonproportionality of the smoking effect on incident diabetes. Potential interactions between cystatin $\mathrm{C}$ and other risk factors were assessed. None were significant at 5\% level.

We considered age, sex, BMI, smoking status, $\mathrm{HbA}_{1 \mathrm{c}}$, hsCRP, chronic kidney disease (CKD) status, hypertension, sedentary lifestyle and gross proteinuria history as potential confounders in multivariate analysis. The distribution of serum cystatin $\mathrm{C}$ was highly skewed and serum cystatin $\mathrm{C}$ was not linearly associated with the outcome variable, so we performed logarithmic transformation of cystatin $\mathrm{C}$ to use in the analysis.

\section{Results}

Of the 4,926 people who participated in the baseline examination, 4,901 had information on diabetes status; $441(9.0 \%)$ had diabetes and $92(1.9 \%)$ were suspected of having diabetes. Of the remaining 4,368 participants without diabetes, 896 (20.5\%) were alive but not examined at the 5 year follow-up examination because of refusal or because they could not be located. Incidence analyses in this report are limited to the remaining 3,472 people at risk of developing diabetes, including 714 people who died at any follow-up examination. People without diabetes incidence data were more likely to be older and, after adjusting for age, were more likely to be current smokers and have a higher mean serum cystatin $\mathrm{C}$ level than participants included in analyses.
The 15 year cumulative incidence of diabetes was estimated to be $9.6 \%$. Characteristics of the study population according to whether the person developed or did not develop diabetes or died are presented in Table 1. While adjusting for age and sex, people with higher levels of serum cystatin $\mathrm{C}$ were more likely to die $(p<0.05)$. Also, people who died had a more frequent history of cardiovascular disease and gross proteinuria history $(p<0.05)$. People who developed diabetes during the 15 year follow-up were older, had higher BMI, and were more likely to be male and an ex-smoker $(p<0.05)$. In addition, people who developed diabetes had higher mean $\mathrm{HbA}_{1 \mathrm{c}}$ levels and mean systolic and diastolic BP at the baseline examination $(p<0.05)$, but did not differ in mean serum total cholesterol levels from people who did not develop diabetes. Also, people who developed diabetes were more likely to be hypertensive, were more likely to have a history of cardiovascular disease and to use beta-blockers, diuretics and non-steroidal antiinflammatory drugs than people who did not develop diabetes. People who developed diabetes had higher serum cystatin C levels and lower cystatin C-based GFR, but did not differ in serum creatinine and creatinine based GFR levels and gross proteinuria status from people who did not develop diabetes.

Our median value and interquartile range for cystatin $\mathrm{C}$ were 0.85 and $0.75-0.99 \mathrm{mg} / \mathrm{l}$, respectively. On the $\log$ scale it corresponded to a median value of $-0.16 \mathrm{mg} / 1$ and interquartile range of -0.29 to $-0.01 \mathrm{mg} / \mathrm{l}$. The geometric mean of cystatin $\mathrm{C}$ was 0.83 for people who did not develop diabetes, $0.90 \mathrm{mg} / 1$ for those who developed diabetes and $1.03 \mathrm{mg} / \mathrm{l}$ for those who died.

The results of multivariate analysis showed that serum cystatin $\mathrm{C}$ at baseline was associated with diabetes development after adjustment for sex and age (Table 2). Further sequential adjustment for BMI, smoking status, $\mathrm{HbA}_{1 \mathrm{c}}$, hypertension history, gross proteinuria and CKD status showed that serum cystatin $\mathrm{C}$ remained associated with the incidence of diabetes (OR per $\log$ of cystatin $\mathrm{C}$ $2.19 ; 95 \%$ CI 1.02-4.68). It corresponded to OR 1.15 (95\% CI $1.01-1.31$ ) per $50 \%$ increase in cystatin C. Serum cystatin $\mathrm{C}$ in our study was weakly correlated with markers of inflammation such as hsCRP $(r=0.19, p=0.0001)$. The association of serum cystatin $\mathrm{C}$ with the incidence of diabetes remained significant after further adjustment for serum C-reactive protein (OR 2.09; 95\% CI 1.02-4.11). Estimated GFR $\left(\mathrm{ml} \mathrm{min} \mathrm{m}^{-1} 1.73 \mathrm{~m}^{-2}\right)$ based on serum cystatin $\mathrm{C}$ levels was related to the incidence of diabetes after controlling for age and sex (OR $0.98 ; 95 \%$ CI $0.97-$ $0.99 ; p<0.0001)$. In contrast, GFR $\left(\mathrm{ml} \mathrm{min} \min ^{-1} 1.73 \mathrm{~m}^{-2}\right)$ based on serum creatinine using the MDRD equation was not related to the incidence of diabetes after controlling for age and sex (OR 1.00; 95\% CI 0.99-1.01, $p=0.94$ ). Stratification by kidney disease status (Table 2) showed 
Table 1 Baseline characteristics by diabetes incidence and death status at the 1988-1990 Beaver Dam Eye Study examination

\begin{tabular}{|c|c|c|c|}
\hline Characteristic & Did not develop T2DM $(n=2,483)$ & Developed T2DM $(n=275)$ & Died $(n=714)$ \\
\hline Age (years) & $58.6 \pm 10.0$ & $60.0 \pm 10.4$ & $70.0 \pm 9.8$ \\
\hline Males, $n(\%)$ & $1,025(41.3)$ & $146(53.1)$ & $375(52.5)$ \\
\hline \multicolumn{4}{|l|}{ BMI, $n(\%)$} \\
\hline $25-29 \mathrm{~kg} / \mathrm{m}^{2}$ & $1,077(43.4)$ & $76(27.6)$ & $275(38.5)$ \\
\hline$\geq 30 \mathrm{~kg} / \mathrm{m}^{2}$ & $753(30.3)$ & $174(63.3)$ & $228(31.9)$ \\
\hline \multicolumn{4}{|l|}{ Smoking history, $n(\%)$} \\
\hline Ex-smoker & $827(33.3)$ & $124(45.1)$ & $284(39.8)$ \\
\hline Current smoker & $477(19.2)$ & $46(16.7)$ & $147(20.6)$ \\
\hline Sedentary lifestyle, $n(\%)$ & $1,829(73.7)$ & $205(74.6)$ & $575(80.5)$ \\
\hline $\mathrm{HbA}_{1 \mathrm{c}}(\%)$ & $5.6 \pm 0.6$ & $6.2 \pm 0.8$ & $5.8 \pm 0.7$ \\
\hline \multicolumn{4}{|l|}{ Serum total cholesterol } \\
\hline $\mathrm{mg} / \mathrm{dl}$ & $232.5 \pm 42.4$ & $235.6 \pm 49.7$ & $230.7 \pm 46.4$ \\
\hline $\mathrm{mmol} / \mathrm{l}$ & $6.02 \pm 1.10$ & $6.10 \pm 1.29$ & $5.98 \pm 1.20$ \\
\hline Systolic BP (mmHg) & $128.4 \pm 18.5$ & $135.0 \pm 19.0$ & $136.1 \pm 22.4$ \\
\hline Diastolic BP (mmHg) & $77.9 \pm 10.1$ & $79.7 \pm 11.3$ & $75.2 \pm 11.7$ \\
\hline Presence of hypertension, $n(\%)$ & $1,037(41.8)$ & $169(61.5)$ & $428(60.1)$ \\
\hline Cardiovascular disease history, $n(\%)$ & $196(8.0)$ & $40(14.6)$ & $193(27.6)$ \\
\hline History of $\beta$-blocker use, $n(\%)$ & $160(6.5)$ & $33(12.0)$ & $72(10.1)$ \\
\hline History of calcium channel blocker use, $n(\%)$ & $39(1.6)$ & $7(2.6)$ & $20(2.8)$ \\
\hline History of diuretic use, $n(\%)$ & $471(19.2)$ & $80(29.9)$ & $266(38.0)$ \\
\hline History of ACE inhibitors use, $n(\%)$ & $111(4.5)$ & $18(6.7)$ & $58(8.2)$ \\
\hline History of NSAID use, $n(\%)$ & $769(31.0)$ & $100(36.4)$ & $271(38.0)$ \\
\hline Presence of gross proteinuria, $n(\%)$ & $52(2.2)$ & $12(4.6)$ & $46(7.0)$ \\
\hline \multicolumn{4}{|l|}{ Serum hsCRP, median (interquartile range) } \\
\hline $\mathrm{mg} / \mathrm{l}$ & $1.67(0.8-3.4)$ & $2.65(1.3-4.8)$ & $2.77(1.3-6.4)$ \\
\hline $\mathrm{nmol} / 1$ & $15.9(7.6-32.3)$ & $25.2(12.4-45.6)$ & $26.3(12.4-60.8)$ \\
\hline \multicolumn{4}{|l|}{ Serum creatinine } \\
\hline $\mathrm{mg} / \mathrm{dl}$ & $0.89 \pm 0.19$ & $0.93 \pm 0.23$ & $1.01 \pm 0.48$ \\
\hline$\mu \mathrm{mol} / 1$ & $78.7 \pm 16.8$ & $82.2 \pm 20.3$ & $89.28 \pm 42.4$ \\
\hline History of $\mathrm{CKD}^{\mathrm{a}}, n(\%)$ & $272(11.5)$ & $34(12.1)$ & $189(29.1)$ \\
\hline $\mathrm{GFR}^{\mathrm{b}}\left(\mathrm{ml} \mathrm{min} \min ^{-1} 1.73 \mathrm{~m}^{-2}\right)$ & $78.1 \pm 16.2$ & $77.6 \pm 17.6$ & $72.1 \pm 22.3$ \\
\hline $\operatorname{GFR}^{\mathrm{c}}\left(\mathrm{ml} \mathrm{min}{ }^{-1} 1.73 \mathrm{~m}^{-2}\right)$ & $91.8 \pm 21.9$ & $82.8 \pm 19.7$ & $69.5 \pm 26.0$ \\
\hline Serum cystatin C (mg/l) & $0.86 \pm 0.19$ & $0.93 \pm 0.22$ & $1.09 \pm 0.43$ \\
\hline
\end{tabular}

Values are mean \pm SD unless stated otherwise

NSAID, non-steroidal anti-inflammatory drug; T2DM, type 2 diabetes mellitus

${ }^{\mathrm{a}} \mathrm{CKD}$ status was defined using serum creatinine as GFR $<60 \mathrm{ml} \mathrm{min}{ }^{-1} 1.73 \mathrm{~m}^{-2}$; ${ }^{\mathrm{b}}$ Based on serum creatinine; ${ }^{\mathrm{c}}$ based on serum cystatin $\mathrm{C}$

that the association of serum cystatin $\mathrm{C}$ with the incidence of diabetes was similar in people with and without CKD (Table 2). The association of serum cystatin $\mathrm{C}$ with the incidence of diabetes was significant after adjustment for age and sex in both groups. BMI was the strongest confounder of the association of cystatin $\mathrm{C}$ with incident diabetes in both groups. The association did not remain significant after adjustment for BMI in persons with kidney disease and after adjustment for $\mathrm{HbA}_{1 \mathrm{c}}$ in persons without kidney disease. In both subgroups, the odds of having incident diabetes was not different after controlling for confounding factors (Table 2).

\section{Discussion}

In our study, while controlling for age, sex, BMI, hypertension status, $\mathrm{HbA}_{1 \mathrm{c}}$ and other risk factors, the serum level of cystatin $\mathrm{C}$ was associated with increased risk of incident type 2 diabetes mellitus. To our knowledge, 
Table 2 Impact of sequential adjustment on cystatin C-related differences in 15 year cumulative diabetes incidence in the Beaver Dam Eye Study

\begin{tabular}{llrl}
\hline Variable & $\begin{array}{l}\text { Overall } \\
(n=3,472)\end{array}$ & $\begin{array}{l}\text { No CKD, no proteinuria } \\
(n=2,706)\end{array}$ & $\begin{array}{l}\text { CKD or proteinuria } \\
(n=571)\end{array}$ \\
\hline${\text { Adjusted for age }{ }^{\mathrm{a}} \text { and sex }}_{\text {Adjusted for all above and BMI }}$ & $4.62(2.52-8.49)$ & $6.74(2.78-16.35)$ & $4.34(1.40-13.43)$ \\
Adjusted for all above and smoking status & $2.51(1.32-4.79)$ & $2.76(1.11-6.87)$ & $2.83(0.89-9.04)$ \\
Adjusted for all above and $\mathrm{HbA}_{1 \mathrm{c}}$ & $2.50(1.30-4.82)$ & $2.52(1.01-6.36)$ & $3.28(0.96-1.02)$ \\
Adjusted for all above and hypertension history & $2.24(1.16-4.33)$ & $2.40(0.91-6.30)$ & $2.54(0.74-8.69)$ \\
Adjusted for all above and gross proteinuria and CKD status & $1.99(1.03-3.85)$ & $2.06(0.79-5.43)$ & $2.26(0.65-7.91)$ \\
\hline
\end{tabular}

Data are OR per log of cystatin C $(95 \% \mathrm{CI})$

The difference between overall group and stratified groups in Table 2 is explained by missing values for proteinuria and/or CKD status in these groups

${ }^{a}$ Age was entered in the analysis as a continuous variable; logarithmic transformation of continuous variable was performed for serum cystatin C

${ }^{\mathrm{b}} \mathrm{CKD}$ status was defined using serum creatinine as GFR $<60 \mathrm{ml} \mathrm{min}^{-1} 1.73 \mathrm{~m}^{-2}$

this is the first long-term population-based study that shows an association of serum cystatin $\mathrm{C}$ with the incidence of type 2 diabetes mellitus. While we found that the effect was independent of the presence of CKD as defined by the MDRD equation and proteinuria, the association may still be due to kidney disease, as suggested by the association of the estimated GFR using a cystatin $\mathrm{C}$ equation with increased risk of diabetes in our study. Serum cystatin $\mathrm{C}$ is thought to be more precise than serum creatinine in defining the presence of early kidney dysfunction [20-22]. It is possible that the preclinical stage of kidney dysfunction, defined by a higher serum cystatin $\mathrm{C}$ than estimated by the MDRD study equation, might explain its relationship to type 2 diabetes incidence in our study. Kidney dysfunction defined by low estimated GFR has been shown by others to be related to the development of diabetes [23]. This has, in part, been thought to be due to insulin resistance [24], increased renal gluconeogenesis [25], endothelial dysfunction and/or chronic inflammation [26, 27], oxidative stress [27] and activation of the reninangiotensin system [28] in persons with CKD.

It is also possible that the relationship of serum cystatin $\mathrm{C}$ to the incidence of diabetes is the result of other disease processes. In people without kidney disease, the association of serum cystatin $\mathrm{C}$ with incident diabetes was significant after controlling for age, sex, BMI and smoking status. However, the association did not remain significant after further adjustment for $\mathrm{HbA}_{1 \mathrm{c}}$. Recent studies suggest that cystatin $\mathrm{C}$ is associated with insulin resistance, obesity and hypertension, conditions closely related to diabetes [3, 4]. Additionally, cystatin $\mathrm{C}$ is related to inflammation and oxidative stress, which are key pathogenetic components of the metabolic syndrome [3]. Oxidative stress has been shown to induce the synthesis of cystatin C mRNA and protein, which may reflect a cellular defensive response to oxidative stress [29]. Higher serum cystatin C values have been shown to be directly related to chronic inflammation [30]. Some studies have linked chronic inflammation to diabetes incidence [31, 32]. The relationship of higher serum levels of cystatin $\mathrm{C}$ to diabetes development in our study might be partially explained by a direct contribution of serum cystatin $\mathrm{C}$ to the interrelated processes of inflammation and endothelial dysfunction, thus increasing the risk of developing diabetes. Our secondary analyses showed that hsCRP attenuated the association between serum cystatin $\mathrm{C}$ and diabetes incidence; however, the relation remained statistically significant.

While our study has many strengths, including the long follow-up, high participation rate and the use of standardised protocols to measure risk factors and diabetes, it also has some limitations. First, the small number of non-white and Hispanic participants may limit the ability to generalise our findings to other ethnic groups. Second, it is possible that selective survival (persons with higher levels of cystatin $\mathrm{C}$ and other risk factors who developed diabetes were less likely to be seen in follow-up because of higher mortality) resulted in underestimation of the relationship between cystatin $\mathrm{C}$ and diabetes. Third, there may be uncontrolled confounding by unmeasured characteristics, such as genetic or nutritional factors, that may be related to cystatin $\mathrm{C}$ and diabetes. Fourth, there may have been misclassification of diabetes in our study. However, when we checked our results, eliminating persons with borderline $\mathrm{HbA}_{1 \mathrm{c}}$ levels ( $\geq 6.0 \%$ but $\leq 6.5 \%$ ), our results yielded the same conclusion.

In summary, serum cystatin $\mathrm{C}$ levels were associated with incident type 2 diabetes independently of confounding risk factors. The exact mechanism is unknown but our results suggest that cystatin $\mathrm{C}$ might serve as a more specific marker than serum creatinine for early stages of $\mathrm{CKD}$, a risk factor for the incidence of diabetes, or it may contribute directly to the pathogenesis of type 2 diabetes mellitus. 
Acknowledgements This project was supported by EY05694 from the National Eye Institute and DK073217 from the National Institute of Diabetes and Digestive and Kidney Diseases, both from the National Institute of Health, Bethesda, MD, USA, and by a MentorBased Postdoctoral Fellowship Award from the American Diabetes Association, Alexandria, VA, USA. The content is solely the responsibility of the authors and does not necessarily reflect the official views of the National Eye Institute, the National Institute of Diabetes and Digestive and Kidney Diseases, or the National Institutes of Health. The authors would like to acknowledge R. E. Gangnon of the University of Wisconsin School of Medicine and Public Health, Population Health Sciences, for his statistical input.

Duality of interest The authors declare that there is no duality of interest associated with this manuscript.

\section{References}

1. Geiss LS, Pan L, Cadwell B, Gregg EW, Benjamin SM, Engelgau MM (2006) Changes in incidence of diabetes in U.S. adults, 1997-2003. Am J Prev Med 30:371-377

2. Kirtland KA, Li YF, Geiss LS, Thompson TJ (2008) State specific incidence of diabetes among adults-participating states, 19951997, and 2005-2007. www.cdc.gov/mmwr/preview/mmwrhtml/ mm5743a2.htm. Accessed 29 January 2011

3. Surendar J, Indulekha K, Aravindhan V, Ganesan A, Mohan V (2010) Association of cystatin-C with metabolic syndrome in normal glucose-tolerant subjects (CURES-97). Diabetes Technol Ther 12:907-912

4. Servais A, Giral P, Bernard M, Bruckert E, Deray G, Isnard BC (2008) Is serum cystatin-C a reliable marker for metabolic syndrome? Am J Med 121:426-432

5. Kahn HS, Cheng YJ, Thompson TJ, Imperatore G, Gregg EW (2009) Two risk-scoring systems for predicting incident diabetes mellitus in U.S. adults age 45 to 64 years. Ann Intern Med 150:741-751

6. Surampudi PN, John-Kalarickal J, Fonseca VA (2009) Emerging concepts in the pathophysiology of type 2 diabetes mellitus. Mt Sinai J Med 76:216-226

7. Donahue RP, Stranges S, Rejman K, Rafalson LB, Dmochowski J, Trevisan M (2007) Elevated cystatin C concentration and progression to pre-diabetes: the Western New York Study. Diabetes Care 30:1724-1729

8. Klein R, Klein BE, Linton KL, de Mets DL (1991) The Beaver Dam Eye Study: visual acuity. Ophthalmology 98:1310-1315

9. Klein R, Klein BE, Lee KE (1996) Changes in visual acuity in a population. The Beaver Dam Eye Study. Ophthalmology 103:1169-1178

10. Klein R, Klein BE, Lee KE, Cruickshanks KJ, Chappell RJ (2001) Changes in visual acuity in a population over a 10 year period: the Beaver Dam Eye Study. Ophthalmology 108:1757-1766

11. Klein R, Klein BE, Lee KE, Cruickshanks KJ, Gangnon RE (2006) Changes in visual acuity in a population over a 15 year period: the Beaver Dam Eye Study. Am J Ophthalmol 142:539-549

12. Klein R, Klein BE (1995) The Beaver Dam Eye Study II. Manual of operations. NTIS Accession No. PB95-273827. US Department of Commerce, Springfield, VA

13. Klein R, Klein BE (1999) The Beaver Dam Eye Study III. Manual of operations. NTIS Accession No. PB99-137861. US Department of Commerce, Springfield, VA
14. Levey AS, Coresh J, Greene T et al (2006) Using standardized serum creatinine values in the modification of diet in renal disease study equation for estimating glomerular filtration rate. Ann Intern Med 145:247-254

15. Stevens LA, Coresh J, Schmid CH et al (2008) Estimating GFR using serum cystatin $\mathrm{C}$ alone and in combination with serum creatinine: a pooled analysis of 3,418 individuals with CKD. Am J Kidney Dis 51:395-406

16. Gooley TA, Leisenring W, Crowley J, Storer BE (1999) Estimation of failure probabilities in the presence of competing risks: new representations of old estimators. Stat Med 18:695-706

17. Cox DR (1972) Regression models and life-tables (with discussion). J R Stat Soc B 34:187-220

18. Kaplan EL, Meier P (1958) Nonparametric estimation from incomplete observations. J Am Stat Assoc 53:457-481

19. Kleinbaum DG (1996) Survival analysis: a self-learning text. Springer, New York

20. Coll E, Botey A, Alvarez L et al (2000) Serum cystatin C as a new marker for noninvasive estimation of glomerular filtration rate and as a marker for early renal impairment. Am J Kidney Dis 36:2934

21. Newman DJ, Thakkar H, Edwards RG et al (1995) Serum cystatin $\mathrm{C}$ measured by automated immunoassay: a more sensitive marker of changes in GFR than serum creatinine. Kidney Int 47:312-318

22. Willems D, Wolff F, Mekhali F, Gillet C (2009) Cystatin C for early detection of renal impairment in diabetes. Clin Biochem 42:108-110

23. Lorenzo C, Nath SD, Hanley AJ, Abboud HE, Gelfond JA, Haffner SM (2009) Risk of type 2 diabetes among individuals with high and low glomerular filtration rates. Diabetologia 52:1290-1297

24. Fox CS, Larson MG, Leip EP, Culleton B, Wilson PW, Levy D (2004) Predictors of new-onset kidney disease in a communitybased population. JAMA 291:844-850

25. Eid A, Bodin S, Ferrier B et al (2006) Intrinsic gluconeogenesis is enhanced in renal proximal tubules of Zucker diabetic fatty rats. $\mathrm{J}$ Am Soc Nephrol 17:398-405

26. Meigs JB, Hu FB, Rifai N, Manson JE (2004) Biomarkers of endothelial dysfunction and risk of type 2 diabetes mellitus. JAMA 291:1978-1986

27. Ramos LF, Shintani A, Ikizler TA, Himmelfarb J (2008) Oxidative stress and inflammation are associated with adiposity in moderate to severe CKD. J Am Soc Nephrol 19:593-599

28. Tikellis C, Wookey PJ, Candido R, Andrikopoulos S, Thomas MC, Cooper ME (2004) Improved islet morphology after blockade of the renin-angiotensin system in the ZDF rat. Diabetes 53:989-997

29. Demircan N, Gurel A, Armutcu F, Unalacak M, Aktunc E, Atmaca H (2008) The evaluation of serum cystatin C, malondialdehyde, and total antioxidant status in patients with metabolic syndrome. Med Sci Monit 14:CR97-CR101

30. Taglieri N, Koenig W, Kaski JC (2009) Cystatin C and cardiovascular risk. Clin Chem 55:1932-1943

31. Hu FB, Meigs JB, Li TY, Rifai N, Manson JE (2004) Inflammatory markers and risk of developing type 2 diabetes in women. Diabetes 53:693-700

32. Hu G, Jousilahti P, Tuomilehto J, Antikainen R, Sundvall J, Salomaa V (2009) Association of serum C-reactive protein level with sex-specific type 2 diabetes risk: a prospective Finnish study. J Clin Endocrinol Metab 94:2099-2105 